\title{
Advances in the management of MEN2: from improved surgical and medical treatment to novel kinase inhibitors
}

\author{
Samuel A Wells Jr \\ Genetics Branch, National Cancer Institute, National Institutes of Health, Bethesda, Maryland, USA \\ Correspondence should be addressed to S A Wells: wellss@mail.nih.gov \\ This paper is part of a thematic review section on 25 Years of RET and MEN2. The guest editors for this section were Lois Mulligan and Frank Weber.
}

\begin{abstract}
Medullary thyroid carcinoma (MTC), a tumor derived from the neural crest, occurs either sporadically or as the dominant component of the type 2 multiple endocrine neoplasia (MEN) syndromes, MEN2A and MEN2B. The discovery that mutations in the $R E T$ protooncogene cause hereditary MTC was of great importance, since it led to the development of novel methods of diagnosis and treatment. For example, the detection of a mutated RET allele in family members at risk for inheriting MEN2A or MEN2B signaled that they would develop MTC, and possibly other components of the syndromes. Furthermore, the detection of a mutated allele created the opportunity, especially in young children, to remove the thyroid before MTC developed, or while it was confined to the gland. The discovery also led to the development of molecular targeted therapeutics (MTTs), mainly tyrosine kinase inhibitors, which were effective in the treatment of patients with locally advanced or metastatic MTC. While responses to MTTs are often dramatic, they are highly variable, and almost always transient, because the tumor cells become resistant to the drugs. Clinical investigators and the pharmaceutical industry are focusing on the development of the next generation of MTTs, which have minimal toxicity and greater specificity for mutated RET.
\end{abstract}

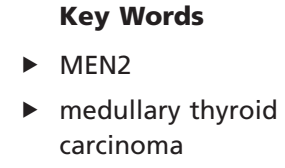

Endocrine-Related Cancer (2018) 25, T1-T13

\section{Introduction}

The description of MEN2A is often attributed to Sipple, who in 1961 reported a patient with a pheochromocytoma (PHEO) and cancer of the thyroid gland (Sipple 1961). In reviewing the literature, he found 537 reports of PHEO and 27 associated malignancies, 6 of which were thyroid cancers. The thyroid cancer in Sipple's patient was described as a poorly differentiated follicular adenocarcinoma, which is understandable, considering that the publication describing medullary thyroid carcinoma (MTC) occurred only 18 months earlier, and many pathologists were unaware of it (Hazard et al. 1959). Also, it would be another 7 years before Steiner and coworkers described a family with MTC, PHEO, hyperparathyroidism (HPTH) and Cushing's syndrome (Steiner et al. 1968). They suggested that 'the entity characterized by tumors of the pituitary, parathyroids and pancreas be designated as multiple endocrine neoplasia (MEN) type 1 , and that the entity characterized by the occurrence of PHEO, MTC and parathyroid tumors be designated as MEN type 2' (Wermer 1954, Steiner et al. 1968). Therefore, the first publication 
describing MEN2A was clearly that of Steiner and coworkers, although earlier publications, including that of Sipple (and the subsequent report that the relatives of his patient had MEN2A), were evidence that the syndrome had existed for some time, but was not recognized as such (Sipple 1961, 1984, Telenius-Berg et al. 1984, Hughes 1996, Neumann et al. 2007). In 1966 two years prior to Steiner's report, Williams and Pollack described 2 patients with MTC, PHEOs, ganglioneuromatosis of the aerodigestive tract and an unusual physical appearance (Williams \& Pollock 1966). The syndrome was thought to be allied to von Recklinghausen's disease, but it was recognized subsequently as being similar to MEN2A and was named MEN2B. Farndon and coworkers described familial medullary thyroid carcinoma (FMTC), a syndrome distinguished by the presence of hereditary MTC, but none of the extrathyroidal manifestations of MEN2A (Farndon et al. 1986). As additional families were studied over subsequent decades, investigators concluded that FMTC was a variant of MEN2A (Wells et al. 2015). Two other conditions occasionally occur in association with MEN2A: cutaneous lichen amyloidosis (CLA) and Hirschsprung's disease (HD) (Gagel et al. 1989, Nunziata et al. 1989, Sijmons et al. 1998, Amiel et al. 2008).

The American Thyroid Association's Task Force to revise the management guidelines for MTC proposed 4 variants of MEN2A: classical MEN2A, characterized by MTC, PHEOs and HPTH; MEN2A and CLA; MEN2A and HD; and FMTC (Wells et al. 2015). Classical MEN2A is characterized by complete penetrance but variable expressivity in that virtually all patients develop MTC, but PHEOs and HPTH occur less frequently, often depending on the presence of a specific RET codon mutation. Also, MEN2A and CLA, and MEN2A and HD are almost always associated with specific RET codon mutations. The presentation of MEN2B is more uniform in that all patients develop MTC, ganglioneuromatosis and the typical phenotype, and more than 60\% develop PHEOs. Generally, the MTC in patients with MEN2B is more aggressive clinically compared to the MTC in patients with MEN2A.

MTC is derived from the thyroid C-cells, which secrete the peptide calcitonin (CTN), and the glycoprotein, carcinoembryonic antigen (CEA). Measurement of serum CTN levels is especially useful in the timing of thyroidectomy in patients who have inherited a mutated RET allele, and in the evaluation of patients following thyroidectomy. The calculation of the time it takes for serum levels of CTN to double provides a reliable index of the rate of tumor growth, and thereby patient prognosis.

\section{The molecular basis of the MEN2 syndromes}

The MEN2 variants and MEN2B are inherited in an autosomal dominant pattern, and each is caused by germline mutations in the RET (rearranged during transfection) protooncogene (Donis-Keller et al. 1993, Mulligan et al. 1993). RET spans 21 exons on chromosome 10 (10q11.2) and encodes a highly conserved single-pass transmembrane receptor of the tyrosine kinase family. The gene is expressed in cells derived from the neural crest: the brain, parasympathetic and sympathetic ganglia, the thyroid C-cells, the adrenal medulla and the urogenital tract (Nakamura et al. 1994).

\section{Characterization of MEN2A}

Classical MEN2A is the most common MEN2A variant, and $95 \%$ of the patients have RET mutations in codons $609,611,618$ or 620 of exon 10, or codon 634 of exon 11. In patients with RET mutations in codon C634, the MTC has an earlier age of onset, and a more aggressive clinical course, compared to that in patients with RET mutations in codons other than C634. If an MTC is more aggressive than that expected with a specific RET codon mutation, it is important to completely sequence the tumor DNA, since a second RET codon mutation may be the reason for the MTC's unexpected behavior (Cerutti \& Maciel 2013).

In patients with RET C634 codon mutations, the incidence of PHEO is $50 \%$ by the 5 th decade and approaches $90 \%$ by the 8 th decade (Imai et al. 2013). In patients with RET codon mutations, other than C634, the incidence of PHEOs ranges from $4 \%$ to $25 \%$ (Table 1). Prior to the advent of genetic screening in families with MEN2A, the most common cause of death was PHEOs not MTC (Lips et al. 1995). HPTH occurs in about 30\% of the patients with MEN2A and RET 634 codon mutations, and is less frequent in patients with mutations in other RET codons (Table 1).

In MEN2A and CLA, the CLA is manifested by the presence of a skin lesion in the scapular region of the back, corresponding to dermatomes T2-T6. The CLA almost always occurs in patients with an RET 634 codon mutation, although there have been reports of CLA in patients with an RET V804 codon mutation, and an RET S891A codon mutation (Gagel et al. 1989, Rothberg et al. 2009, Qi et al. 2015, Scapineli et al. 2016). Originally, CLA was thought to be uncommon, but it has been reported to occur in $35 \%$ of the patients with an RET 634 codon mutation (Verga et al. 2003). Patients may be 
Table 1 Relationship of common RET mutations to risk of aggressive MTC in MEN2A and MEN2B, and to the incidence of PHEO, HPTH, CLA and HD in MEN2A. Reproduced, with permission, from Wells et al. (2015). Copyright 2015 American Thyroid Association and Mary Ann Liebert Inc.

\begin{tabular}{|c|c|c|c|c|c|c|}
\hline RET mutation & Exon & MTC risk levela & Incidence of PHEOb & Incidence of HPTHb & CLAc & HDc \\
\hline G533C & 8 & MOD & + & - & $\mathrm{N}$ & $\mathrm{N}$ \\
\hline C609F/G/R/S/Y & 10 & MOD & $+/++$ & + & $\mathrm{N}$ & $Y$ \\
\hline C611F/G/S/Y/W & 10 & MOD & $+/++$ & + & $\mathrm{N}$ & $Y$ \\
\hline C618F/R/S & 10 & MOD & $+/++$ & + & $\mathrm{N}$ & $Y$ \\
\hline CF20F/R/S & 10 & MOD & $+/++$ & + & $\mathrm{N}$ & $Y$ \\
\hline C630R/Y & 11 & MOD & $+/++$ & + & $\mathrm{N}$ & $\mathrm{N}$ \\
\hline D631Y & 11 & MOD & +++ & - & $\mathrm{N}$ & $\mathrm{N}$ \\
\hline C634F/G/R/S/W/Y & 11 & $\mathrm{H}$ & +++ & ++ & $\mathrm{Y}$ & $\mathrm{N}$ \\
\hline K666E & 11 & MOD & + & - & $\mathrm{N}$ & $\mathrm{N}$ \\
\hline E768D & 13 & MOD & - & - & $\mathrm{N}$ & $\mathrm{N}$ \\
\hline L790F & 13 & MOD & + & - & $\mathrm{N}$ & $\mathrm{N}$ \\
\hline V804L & 14 & MOD & + & + & $\mathrm{N}$ & $\mathrm{N}$ \\
\hline V804M & 14 & MOD & + & + & $\mathrm{Y}$ & $\mathrm{N}$ \\
\hline A883F & 15 & $\mathrm{H}$ & +++ & - & $\mathrm{N}$ & $\mathrm{N}$ \\
\hline S891A & 15 & MOD & + & + & $\mathrm{N}$ & $\mathrm{N}$ \\
\hline R912P & 16 & MOD & - & - & $\mathrm{N}$ & $\mathrm{N}$ \\
\hline M918T & 16 & HST & +++ & - & $\mathrm{N}$ & $\mathrm{N}$ \\
\hline
\end{tabular}

aRisk of aggressive MTC: MOD, moderate; H, high; HST, highest; MTC, medullary thyroid carcinoma; PHEO, pheochromocytoma; HPTH, hyperparathyroidism; CLA, cutaneous lichen amyloidosis; HD, Hirschsprung's disease; bincidence of PHEO and HPTH; ${ }^{C}$, positive occurrence; N, negative occurrence: $+=\sim 10 \%,++=\sim 0-30 \%,+++=\sim 5-\%$.

asymptomatic, but most of them complain of localized pruritus and persistent scratching that result in thickened hyperpigmented skin. In youngsters, the CLA may precede clinical evidence of MEN2A, and thereby serve as a marker for the presence of a mutated RET allele, and the impending development of MTC.

HD occurs in approximately $7 \%$ of the patients with MEN2A; conversely, 2-5\% of the patients with HD have MEN2A (Decker \& Peacock 1998, Sijmons et al. 1998). In MEN2A and HD, the HD occurs in patients with RET codon mutations in exon 10: 609 (15\%), 611 (5\%), 618 (30\%) and 620 (50\%) (Mulligan et al. 1994, Borst et al. 1995). RET mutations also occur in approximately 50\% of the patients with hereditary HD, and in 20\%-33\% of the patients with sporadic HD (Romeo et al. 1994, Amiel et al. 2008). The RET mutations in HD are 'loss of function' mutations that disable RET activation, whereas the RET mutations in MEN2A are 'gain of function' mutations that induce constitutive activation of RET. It seems paradoxical that HD should develop in patients with MEN2A; the explanation being that the RET mutations in exon 10 are sufficient to trigger neoplastic transformation of the thyroid C-cells and the adrenal chromaffin cells, but are insufficient to express the RET protein at the cell surface, resulting in a failed trophic response in precursor neurons (Asai et al. 2006). It is important to screen for MEN2A in patients with HD and to screen for HD in patients with MEN2A and exon 10 mutations.
FMTC, initially thought to be a stand-alone entity, different from MEN2A and MEN2B, is now considered a variant of MEN2A. Many families, classified as FMTC variants, move forthwith into the classical MEN2A category if a single family member develops a PHEO or HPTH (Oliveira et al. 2011).

\section{Characterization of MEN2B}

MEN2B accounts for 5\% of the hereditary MTCs and is characterized by the presence of MTC, PHEOs, ganglioneuromatosis of the aerodigestive tract and a typical phenotype, consisting of a marfanoid habitus, typical facies and skeletal abnormalities. Over $75 \%$ of the cases of MEN2B are sporadic, the result of de novo RET mutations in a normal appearing parent-almost always the father (Carlson et al. 1994). The mean age at diagnosis is 14.2 years and despite the typical phenotype, patients often go unrecognized until the MTC has spread beyond the thyroid gland and is incurable. In families with hereditary MEN2B, the disease may be apparent at, or soon after birth, when thyroidectomy may be curative; however, the MTC is aggressive in this setting, and rare infants have regional lymph node metastases at the time of thyroidectomy (Zenaty et al. 2009). Approximately 95\% of the patients with MEN2B have an RET M918T codon mutation, and the remainder have an $R E T A 833 F$ codon mutation 
(Eng et al. 1994, Gimm et al. 1997) The MTC appears to be less aggressive in patients with the RET A833F codon mutation compared to the MTC in patients with an RET M918T codon mutation (Jasim et al. 2011).

Over 100 RET point mutations, duplications, insertions, deletions or fusions have been identified in patients with MEN2A, whereas only two RET mutations have been identified in patients with MEN2B (Wells et al. 2015). The most common RET mutations occurring in patients with MEN2A and MEN2B, the associated aggressiveness of the MTC and the frequency of the MEN2 variants, PHEOs and HPTH, are shown in Table 1.

Although RET mutations appear to be the sole driver in patients with the MEN2 syndromes, there are RET variants of unknown significance (VUS) that are neither benign polymorphisms nor active pathogenic mutations. Family members with the same VUS should be followed expectantly (Crockett et al. 2011).

\section{Sporadic MTC}

In $75 \%$ of the patients with MTC, the disease is sporadic arising from somatic de novo RET mutations. Approximately $40 \%$ of the patients have RET M918T codon mutations, and approximately $30 \%$ have RAS mutations, most often KRAS or HRAS (Moura et al. 2011, 2015) In patients with sporadic MTC, an RETM918T codon mutation is associated with a more aggressive clinical course, compared to that in patients with RAS mutations (Elisei et al. 2008). Genetic screening is important in patients with presumed sporadic MTC, since $7-15 \%$ of them will be found to have an RET germline mutation and hereditary MTC (Eng et al. 1995, Romei et al. 2011, Kihara et al. 2016).

\section{Management of MTC}

In families with MEN2A, it is critical to establish a genetic screening program to identify members who have inherited a mutated RET allele and offer them genetic counseling. In most kindreds with MEN2A, family members decide to have a thyroidectomy if they are found to have a mutated RET allele or clinical evidence of MTC. Some elderly patients who have an RET mutation do not wish to have a thyroidectomy, even if they have a thyroid nodule. Most adult members of families with MEN2A advise a thyroidectomy in their children, since it is the only cure for MTC, assuming that the tumor has not developed, or is confined to the thyroid gland. Even though the procedure is usually referred to as a prophylactic thyroidectomy, and indeed a few patients have no evidence of a C-cell disorder in the thyroidectomy specimen, the majority of patients have C-cell hyperplasia, or small foci of MTC. Therefore, a better term for the procedure is early thyroidectomy.

Before the discovery of RET mutations in patients with MEN2A, the detection of an elevated serum calcitonin level served as the basis for timing thyroidectomy. Although this strategy was useful, the frequency of false positive values led to unnecessary operations (Marsh et al. 1996). Following the discovery of RET mutations as the cause of MEN2, oncologists based the timing of thyroidectomy largely on the presence of a specific RET codon mutation. There were also problems with this strategy, since there is substantial variability in the age at which MTC develops, not only among different families with the same RET codon mutation, but among individuals within the same family. Currently, the generally accepted practice is to use a combination of genetic testing and the basal or stimulated serum calcitonin level to decide the timing of thyroidectomy.

Generally, in patients with MEN2A, and an RET C634 codon mutation, the thyroid should be removed around 5 years of age. The surgeon can avoid dissecting the central zone of the neck, since lymph node metastases rarely occur by this age. When there is no central zone dissection, the parathyroid glands can be left in situ if they are normal in size, realizing that the patient may develop HPTH later in life. In the unusual situation where the parathyroid glands are enlarged, they can be managed by radical subtotal $3^{1 / 2}$ gland resection or total parathyroidectomy with heterotopic autotransplantation. Whatever the mode of management, it is important to preserve parathyroid function, since without it, the patient is committed to lifelong dependency on calcium and vitamin D replacement therapy, and is also vulnerable to the potential complications associated with chronic hypocalcemia.

Measurement of the serum calcitonin level, in the basal state or following stimulation with pentagastrin, or calcium, or both, is the most reliable way to detect persistent or residual MTC after thyroidectomy (Skinner et al. 2005). Some investigators consider that a basal serum calcitonin level within the normal range or a pentagastrinstimulated serum calcitonin less than $10 \mathrm{pg} / \mathrm{mL}$ following thyroidectomy represents a 'biochemical cure' (Barbot et al. 1994, Franc et al. 2001). A detectable basal postoperative serum CTN, even within the normal range, represents an incurable state, although the progression of the MTC is variable, and patients may go for years before they develop a clinical recurrence, if they ever 
do. In one study, 50 consecutive youngsters with a germline $R E T$ mutation were evaluated at least 5 years after prophylactic thyroidectomy (Skinner et al. 2005). The basal and stimulated (with the combined intravenous infusion of pentagastrin and calcium) serum calcitonin levels were undetectable in $44(88 \%)$ patients, but were elevated in 2 patients, one immediately postoperatively and the other at 3 years postoperatively. In 4 patients, the basal serum calcitonin levels were undetectable at every evaluation time point, but the stimulated calcitonin levels were above the normal range from 4 to 10 years after thyroidectomy (Fig. 1).

Prophylactic thyroidectomy, although extremely useful in youngsters, applies to a small number of patients with hereditary MTC, and no patients with sporadic MTC. In newly discovered families with MEN2A, one finds all stages of disease. In $75 \%$ of the patients with clinically evident thyroid nodules, the MTC has already spread to regional lymph nodes, and $10 \%$ of the patients have metastases at distant sites (Weber et al. 2001, Moley 2010). In some patients, even the elderly, the MTC is occult, the only evidence of its presence being an elevated serum calcitonin level. The management algorithm for patients found to have an RET germline mutation is shown in Fig. 2.

The preferred operation for most patients is total thyroidectomy with dissection of lymph nodes in the central neck. Additional lymph node compartments are dissected if there is evidence of metastases on preoperative imaging studies, or at the time of thyroidectomy.
Lifelong follow-up is indicated, beginning every three months postoperatively, and at longer intervals if there is no evidence of persistent or recurrent disease in the first year after thyroidectomy. Serial measurements of serum calcitonin and CEA levels are useful in documenting disease progression, and especially in the calculation of the time that it takes for the two markers to double. In a recent study of 65 patients, the 10-year survival was $8 \%$ in patients whose serum CTN doubling time was less than 6 months, $37 \%$ in patients with doubling times between 6 and 24 months and 96\% in patients with doubling times greater than 24 months (Barbet et al. 2005). When the doubling times of serum CEA and serum calcitonin are concordant, the predictability of disease progression and prognosis is more accurate (Laure Giraudet et al. 2008).

\section{Management of PHEO}

Half or more of the patients with MEN2A and MEN2B develop PHEOs, the incidence increasing with age. The diagnosis of a PHEO succeeds the diagnosis of MTC in $\sim 50 \%$ of the patients, is coterminous with the diagnosis of MTC in $~ 40 \%$ of the patients and precedes the diagnosis of MTC in $\sim 10 \%$ of the patients (Rodriguez et al. 2008). The PHEOs are almost always benign, multicentric and confined to the adrenal gland (Modigliani et al. 1995). Regardless of whether the patient has MEN2A or MEN2B, it is critical to exclude the presence of a PHEO prior to any diagnostic or therapeutic intervention. Following resection

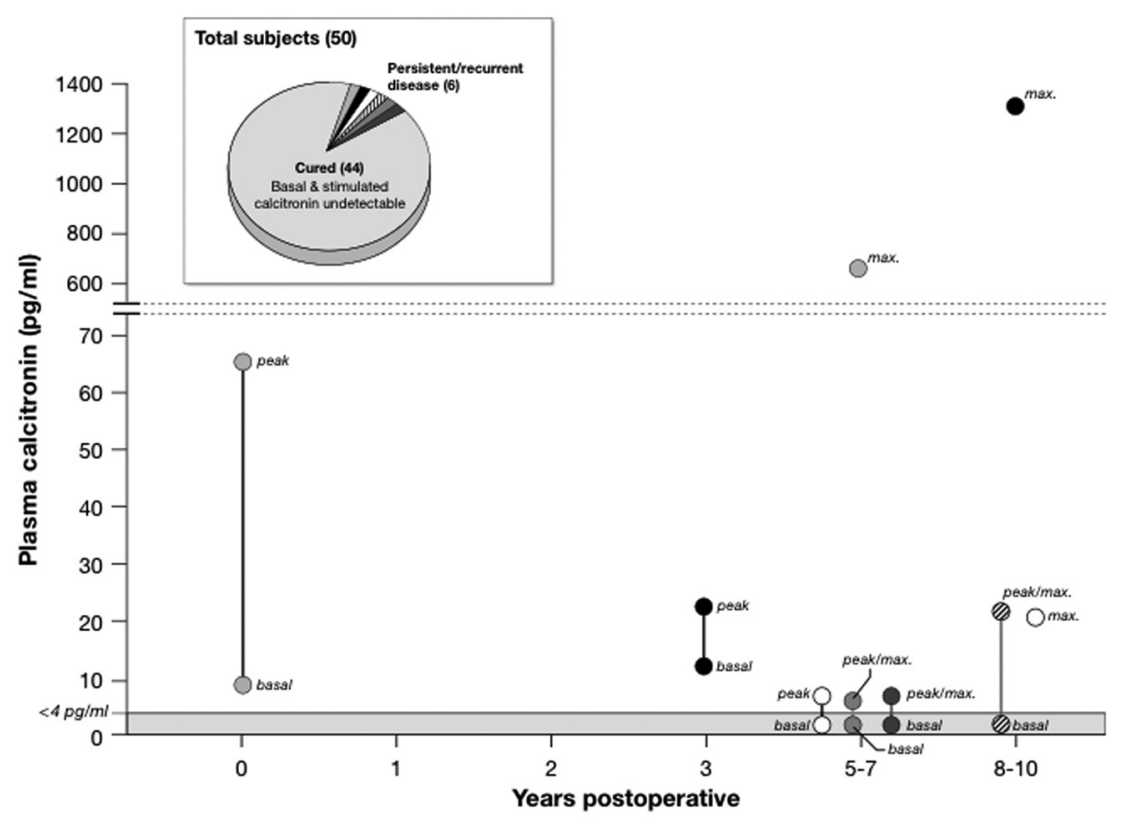

Figure 1

The results of 50 consecutive patients (mean age 10 years; range 3-19 years) who had inherited a mutated RET allele and were treated by prophylactic thyroidectomy. All patients were evaluated $5-10$ years after surgery (mean 7 years) by physical examination and measurement of serum calcitonin levels following the combined administration of calcium and pentagastrin. Basal and stimulated serum calcitonin levels were undetectable in 44 patients, and they were considered cured. Basal serum calcitonin levels were undetectable in 4 patients but they increased above the normal range following stimulation 4-9 years after thyroidectomy. In two patients, basal and stimulated serum calcitonin levels were above the normal range, one immediately after thyroidectomy and the other not until 3 years after thyroidectomy. Data from Skinner et al. (2005). 


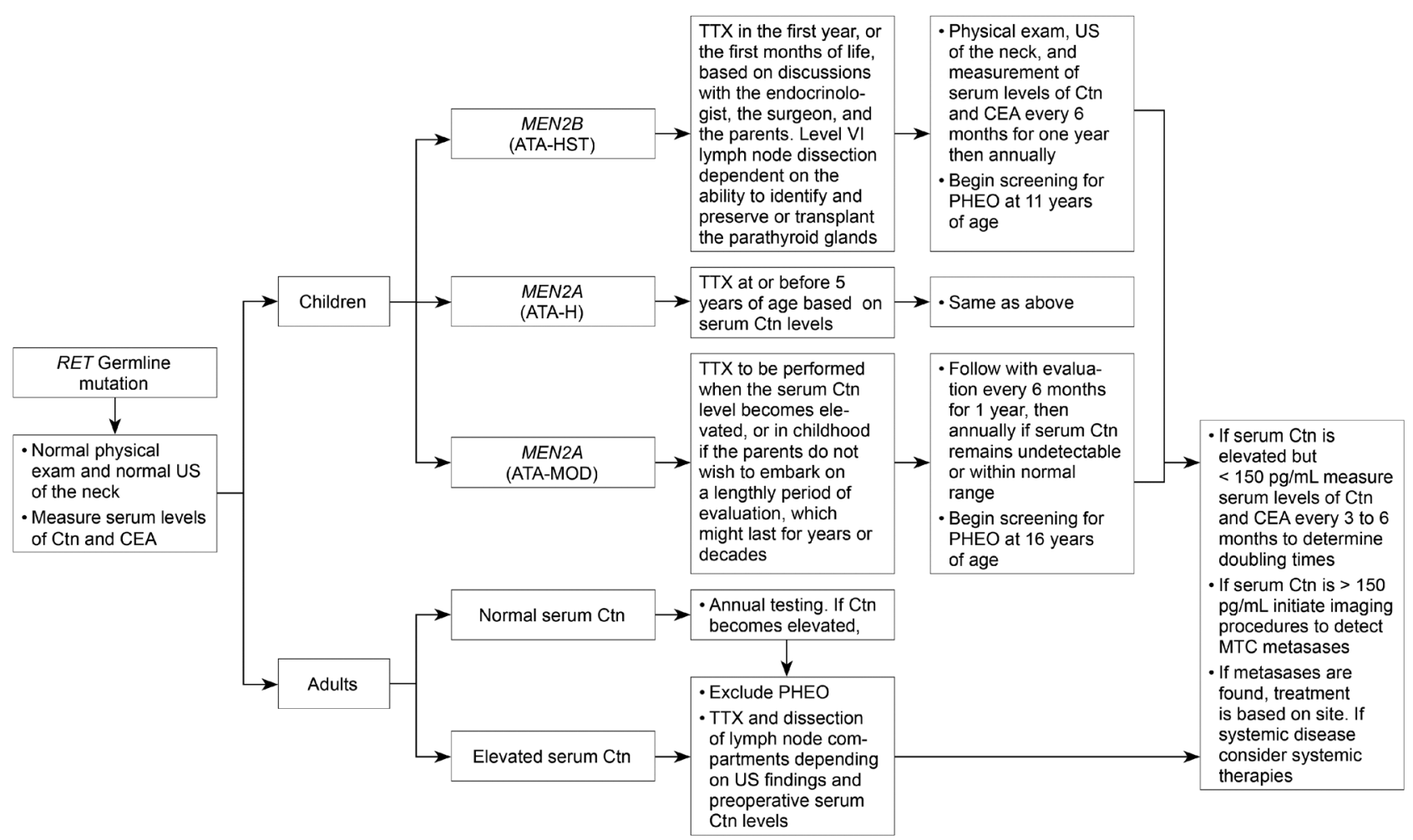

Figure 2

Management of patients with an RET germline mutation detected on genetic screening. ATA, American Thyroid Association risk categories for aggressive medullary thyroid carcinoma (MTC) (HST, highest risk, H, high risk, MOD, moderate risk); Ctn, calcitonin; CEA, carcinoembryonic antigen; HPTH, hyperparathyroidism; PHEO, pheochromocytoma; RET, REarranged during Transfection; TTX, total thyroidectomy; US, ultrasound: Reproduced, with permission, from Wells et al. (2015). Copyright 2015 American Thyroid Association and Mary Ann Liebert Inc.

of one or more PHEOs, prolonged evaluation is important for two reasons. In the majority of patients, a contralateral PHEO will develop within 10 years after a unilateral adrenalectomy (Lairmore et al. 1993, Asari et al. 2006). Following a bilateral adrenalectomy, patients are at risk for an Addisonian crisis, especially if they become injured, or ill, or receive inadequate glucocorticoid replacement (Lairmore et al. 1993). Recognizing the complications associated with bilateral adrenalectomies, surgeons have recently turned to performing subtotal adrenalectomies in an attempt to preserve sufficient adrenal cortical tissue and obviate the need for glucocorticoid replacement, even under stressful conditions. Thus far, the experience has been mixed, as about half of the patients require supplemental glucocorticoids, and from 3\% to $20 \%$ of the patients develop a recurrent PHEO at some time after surgery (Brauckhoff et al. 2008, Scholten et al. 2011, Brauckhoff \& Dralle 2012). Cortical sparing adrenalectomy seems promising; however, long-term evaluation of many patients is necessary before the worth of the technique is established.

\section{Management of HPTH}

HPTH occurs in approximately 30\% of the patients with MEN2A, most often in patients with RET mutations in exon 10 and exon 11, especially RET codon C634. The mean age at diagnosis is 33.7 years. The HPTH is usually mild and asymptomatic, but surgical resection is indicated if patients develop symptoms or signs related to hypercalcemic. The surgical options are either subtotal $3^{1 / 2}$ gland resection or total parathyroidectomy with a parathyroid autograft to a heterotopic site. The size of the individual parathyroid glands may vary, and the surgeon may be tempted to remove only those that are enlarged; however, this approach carries the risk that patients will develop persistent or recurrent HPTH. It is important that the surgeon identifies and marks the sites of parathyroid glands left in situ in order to identify them if the patient develops HPTH and requires reoperative surgery. The development of HPTH in patients who have had a prior thyroidectomy presents a challenge for the surgeon. Localization procedures, such as ultrasound, CT scans and 
sestamibi scans, are useful to identify parathyroid glands prior to repeated exploration of the neck.

\section{Management of patients with persistent or recurrent MTC}

Patients who have a total thyroidectomy for MTC are evaluated at varying intervals by physical examination and laboratory tests, including measurement of serum levels of CTN and CEA. Imaging studies are indicated if the serum CTN level exceeds $150 \mathrm{pg} / \mathrm{mL}$, or if there is clinical evidence of recurrent MTC. Repeat operations in patients with regional node metastases are rarely curative, and the treatment of patients with distant metastases is palliative (Scollo et al. 2003, Pelizzo et al. 2007, Wells et al. 2015).
In patients whose advanced MTC is not amenable to surgery, the treatment options are chemotherapy, a molecular targeted therapeutic (MTT) or continued observation (Fig. 3).

\section{Chemotherapy}

Formerly, either single agent or combination chemotherapy was front-line therapy for patients with advanced MTC; however, with most regimens, responses were infrequent and of short duration. Doxorubicin was the first chemotherapeutic that the FDA approved for the treatment of patients with advanced thyroid cancer, but it is seldom given alone, and is more often combined with either vindesine or cisplatin (Gottlieb et al. 1972,

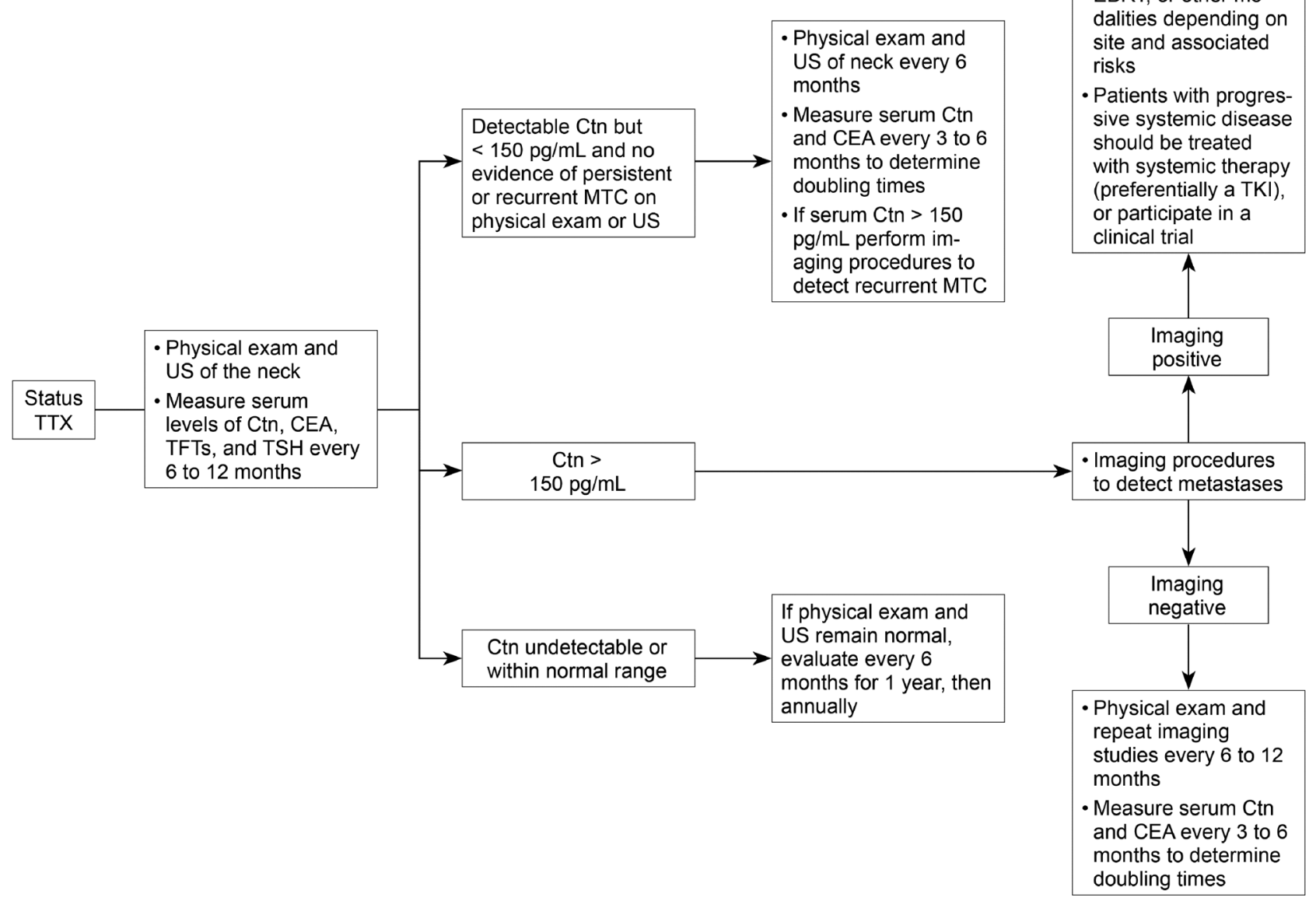

Figure 3

Management of patients following thyroidectomy for persistent or recurrent medullary thyroid carcinoma. Ctn, calcitonin; CEA, carcinoembryonic antigen; EBRT, external beam radiotherapy; MTC, medullary thyroid carcinoma; TFTs, thyroid function tests; TSH, thyrotropin; TKI, tyrosine kinase inhibitor; TTX, total thyroidectomy; US, ultrasound. Reproduced, with permission, from Wells et al. (2015). Copyright 2015 American Thyroid Association and Mary Ann Liebert Inc.

- Consider treating regional disease by surgical resection, EBRT, or other mo dalities depending on

Patients with progressive systemic diseas uld be treated herapy

- If serum Ctn > 150 aging proced months for 1 year, then Physical exam and months doubling times 
Husain et al. 1978, Scherubl et al. 1990). The combined regimen of dacabarzine, vincristine and cyclophosphamide is moderately efficacy in patients with advanced MTC, and is currently the chemotherapeutic regimen of choice for patients with advanced MTC who have failed to respond to, or become resistant to, MTTs (Wu et al. 1994, Deutschbein et al. 2011, Tuttle et al. 2014).

\section{External beam radiation (EBRT)}

EBRT as adjuvant therapy is not indicated in patients with primary MTC, and is of little benefit in the treatment of patients with regional metastases, unless there is impending invasion of vital structures. EBRT is often palliative in patients with metastases to distant sites, such as brain or bone.

\section{Molecular targeted therapeutics}

In the normal state, external growth factors or ligands bind to cell surface receptor tyrosine kinases and transmit a series of intracellular signals. Mutations in these receptors lead to a state of constitutive activation with continuous signaling to the nucleus and immortalization of the cell. Recognizing that the mutated receptors are vulnerable targets, clinical investigators in collaboration with the pharmaceutical industry began to develop specific MTTs for patients with advanced malignancies. The first MTT to show efficacy in patients with a malignant disease (chronic myelogenous leukemia (CML)) was the tyrosine kinase inhibitor (TKI), gleevec (imatinib) (Druker et al. 2001). In a clinical trial of imatinib in patients with CML, there was, at 10.9 years, an overall survival of $83.3 \%$ and a complete cytogenetic remission of $82.8 \%$ (Hochhaus et al. 2017). The efficacy of imatinib in trials of patients with CML created great excitement among oncologists. Unfortunately, the experience with gleevec has not been replicated with various MTTs in patients with solid organ malignancies; however, in patients with advanced MTC, there have been encouraging results in clinical studies of 2 MTTs.

The first TKI approved by the FDA for any thyroid cancer was ZD6474, or vandetanib, an orally available anilinoquinazoline that in preclinical studies blocked the enzymatic activity of RET-derived oncoproteins at a onehalf maximal inhibitory concentration of $100 \mathrm{nM}$. Also in nude mice, ZD6474 blocked the formation of tumors derived from NIH-RET/PTC3 cells (Carlomagno et al. 2002). In a phase II trial of vandetanib in patients with locally advanced or metastatic MTC, the drug administered in a maximum tolerated dose of $300 \mathrm{mg} /$ day induced partial remissions in 6 of the 30 patients, and disease stabilization in 22 patients. The estimated progression-free survival (PFS) was 27.9 months (Wells et al. 2010). Another trial of patients treated with vandetanib, $100 \mathrm{mg} /$ day, gave similar results (Robinson et al. 2010). Supported by the results of the phase II trials, investigators initiated a prospective, double-blind, randomized, phase III trial, evaluating the efficacy of vandetanib, compared to placebo in patients with advanced MTC (Wells et al. 2012). There was an estimated median PFS of 30.5 months in patients treated with vandetanib, compared to 19.3 months in patients receiving placebo (Table 2). Because of grade III adverse events, primarily diarrhea, rash, hypertension and headache, $35 \%$ of the patients required dose reductions. Based on results of the phase III trial, the FDA approved vandetanib for the treatment of patients with progressive, advanced metastatic MTC (Wells et al. 2012).

XL184, or cabozantinib, an orally available TKI with activity against MET, VEGFR2 and RET, prevented phosphorylation of target kinases, reduced cell growth and inhibited angiogenesis and tumor invasiveness in several cell lines (Yakes et al. 2011). In a phase I/II trial of cabozantinib in patients with advanced MTC, 29\% had a partial remission and $68 \%$ had stable disease (Kurzrock et al. 2011). In a subsequent phase III prospective, doubleblind, randomized trial of cabozantinib compared to placebo in patients with advanced MTC, the PFS in patients receiving cabozantinib was longer than that in patients receiving placebo (11.2 months compared to 4 months (Table 2). Grade 3 or 4 adverse events, including hemorrhage, fistulas and gastrointestinal perforation occurred in $69 \%$ of the patients treated with cabozantinib, and there were 9 deaths related to cabozantinib treatment. Based on the results of the phase III clinical trial, the FDA approved cabozantinib for the treatment of patients with advanced MTC (Elisei et al. 2013).

Other MTTs have shown efficacy in patients with advanced MTC, but none has been evaluated in phase III clinical trials (Table 2). Some of the compounds are used as second line therapy in patients who fail treatment with either vandetanib or cabozantinib. The agent most often used is sorafenib, a multikinase inhibitor, which has shown efficacy in phase I and phase II clinical trials of patients with MTC. The most common response has been disease stabilization (Lam et al. 2010, Capdevila et al. 2012).

The experience with MTTs in the treatment of patients with advanced MTC has been sobering. While vandetanib and cabozantinib have improved PFS, there has been no improvement in overall survival. Moreover, 
Table 2 Clinical trials with molecular targeted therapeutics in patients with medullary thyroid carcinoma. Reproduced from Wells SA Jr, Pacini F, Robinson BG \& Santoro M, Multiple endocrine neoplasia type 2 and familial medullary thyroid carcinoma: an update, Journal of Clinical Endocrinology and Metabolism, 2013, volume 98, pages 3149-3164, with permission from the Endocrine Society and Oxford University Press.

\begin{tabular}{l}
\hline Drug (ref) \\
\hline Axitinib (Cohen et al. 2008) \\
Motesanib (Schlumberger et al. 2009) \\
Sorafenib (Lam et al. 2010) \\
Sunitinib (Ravaud et al. 2010) \\
Vandetanib (Wells et al. 2010) \\
Vandetanib (Robinson et al. 2010) (100 mg/day) \\
Cabozantinib (Kurzrock et al. 2011) \\
Vandetanib (Wells et al. 2012) \\
Cabozantinib (Elisei et al. 2013) \\
Imatinib (de Groot et al. 2007) \\
Imatinib (Frank-Raue et al. 2007) \\
Sorafenib plus Tipifarnib (Hong et al. 2011)
\end{tabular}

\begin{tabular}{l}
\hline Study \\
\hline Phase II \\
Phase II \\
Phase II \\
Phase II \\
Phase II \\
Phase II \\
Phase II \\
Phase III \\
Phase III \\
Phase II \\
Phase II \\
Phase II \\
\hline
\end{tabular}

\begin{tabular}{c}
\hline No. pts. \\
\hline 11 \\
91 \\
16 \\
6 \\
30 \\
19 \\
37 \\
$231 / 100$ \\
$219 / 111$ \\
15 \\
9 \\
13
\end{tabular}

\begin{tabular}{c}
\hline PR (\%) \\
\hline 18 \\
2 \\
6.3 \\
50 \\
20 \\
16 \\
29 \\
HR 0.46 \\
HR 0.28 \\
0 \\
0 \\
38 \\
\hline
\end{tabular}

\begin{tabular}{c}
\hline SD (\%) \\
\hline $27 *$ \\
$48^{* *}$ \\
$87.5^{*}$ \\
$\mathrm{NA}$ \\
$53^{* *}$ \\
$53^{* *}$ \\
$41 * *$ \\
0.46 (ORR) \\
0.28 (ORR) \\
$27 * *$ \\
$56 *$ \\
$31 * *$ \\
\hline
\end{tabular}

\begin{tabular}{c}
\hline PFS (mos.) \\
\hline NA \\
12 \\
17.9 \\
NA \\
$27.9^{\#}$ \\
NA \\
NA \\
$30.5^{\#}$ \\
$11.2^{\#}$ \\
0 \\
0 \\
17
\end{tabular}

*>4 mos; **>6 mos; "estimated PFS in months.

$\mathrm{HR}$, hazard ratio comparing PFS in treated compared to placebo control patients; mos., months; NA, not available; No. pts., number of patients; ORR, overall response rate; PFS, progression-free survival; PR, partial response (RECIST); Ref, reference; SD, stable disease.

virtually all responses have been partial, not complete, and almost all patients become resistant to the therapy and develop progressive disease. For unknown reasons, the response to therapy can vary markedly, as noted in Fig. 4, which shows results of vandetanib treatment in 16 children with advanced MTC. Except for one child with sporadic MTC, all children had MEN2B and the M918T RET mutation, all received the same drug, and all of them looked alike; yet their responses to vandetanib varied from a $\sim 10 \%$ to an $\sim 80$ reduction in tumor size. One would expect a similar response rate among the children in the study; yet the responses of the patients were no different from that seen in a more disparate patient population of adults with sporadic MTC, who were treated with vandetanib (Robinson et al. 2010, Wells et al. 2012).
Thus, the response to a given MTT is multifactorial and depends not only on the specific target mutation, and the treatment drug, but on unknown factors in the host. Considering the varied responses and the associated toxicities to the current MTTs used to treat patients with MTC, the pharmaceutical industry is concentrating on the development of MTTs that have minimal toxicity and a greater specificity for inhibiting mutated RET. Two such drugs (BLU-667 (NCT03037385); Blueprint Medicines, Inc., Cambridge, MA, USA) and (LOXO-292 (NCT03157128); Loxo Oncology, Stamford, CT, USA) are currently being evaluated in phase II clinical trials. The goal is to cure patients with advanced MTC, or at least convert their progressive disease to one that is chronic and longlasting.

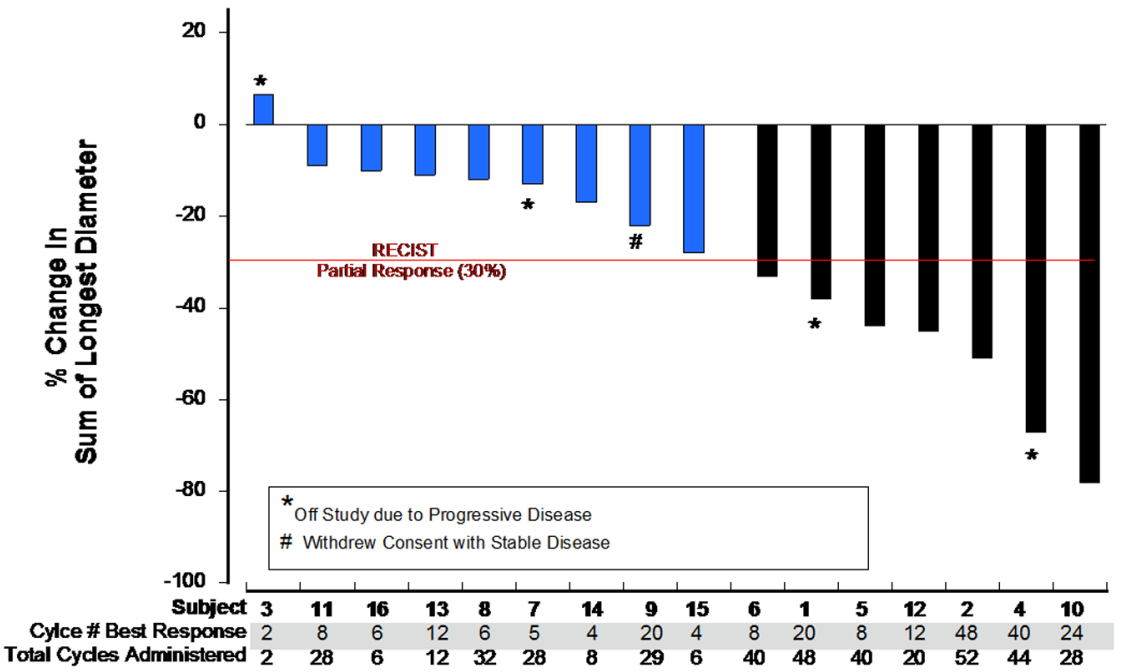

Figure 4

A waterfall plot showing reduction in size of metastatic MTC in children with MEN2B who received vanetanib. Reproduced from Fox et al. (2013), with permission from the American Association for Cancer Research. 


\section{Declaration of interest}

The author declares that there is no conflict of interest that could be perceived as prejudicing the impartiality of this review.

\section{Funding}

This work did not receive any specific grant from any funding agency in the public, commercial or not-for-profit sector.

\section{References}

Amiel J, Sproat-Emison E, Garcia-Barcelo M, Lantieri F, Burzynski G, Borrego S, Pelet A, Arnold S, Miao X, Griseri P, et al. 2008 Hirschsprung disease, associated syndromes and genetics: a review. Journal of Medical Genetics 45 1-14. (https://doi.org/10.1136/ jmg.2007.053959)

Asai N, Jijiwa M, Enomoto A, Kawai K, Maeda K, Ichiahara M, Murakumo Y \& Takahashi M 2006 RET receptor signaling: dysfunction in thyroid cancer and Hirschsprung's disease. Pathology International 56 164-172. (https://doi. org/10.1111/j.1440-1827.2006.01942.x)

Asari R, Scheuba C, Kaczirek K \& Niederle B 2006 Estimated risk of pheochromocytoma recurrence after adrenal-sparing surgery in patients with multiple endocrine neoplasia type 2A. Archives of Surgery 141 1199-1205. (https://doi.org/10.1001/ archsurg.141.12.1199)

Barbet J, Campion L, Kraeber-Bodere F, Chatal JF \& Group GTES 2005 Prognostic impact of serum calcitonin and carcinoembryonic antigen doubling-times in patients with medullary thyroid carcinoma. Journal of Clinical Endocrinology and Metabolism 90 6077-6084. (https://doi.org/10.1210/jc.2005-0044)

Barbot N, Calmettes C, Schuffenecker I, Saint-Andre JP, Franc B, Rohmer V, Jallet P \& Bigorgne JC 1994 Pentagastrin stimulation test and early diagnosis of medullary thyroid carcinoma using an immunoradiometric assay of calcitonin: comparison with genetic screening in hereditary medullary thyroid carcinoma. Journal of Clinical Endocrinology and Metabolism 78 114-120.

Borst MJ, VanCamp JM, Peacock ML \& Decker RA 1995 Mutational analysis of multiple endocrine neoplasia type $2 \mathrm{~A}$ associated with Hirschsprung's disease. Surgery 117 386-391. (https://doi. org/10.1016/S0039-6060(05)80057-1)

Brauckhoff M \& Dralle H 2012 Function-preserving adrenalectomy for adrenal tumors. Chirurg 83 519-527. (https://doi.org/10.1007/ s00104-011-2192-7)

Brauckhoff M, Stock K, Stock S, Lorenz K, Sekulla C, Brauckhoff K, Thanh PN, Gimm O, Spielmann RP \& Dralle H 2008 Limitations of intraoperative adrenal remnant volume measurement in patients undergoing subtotal adrenalectomy. World Journal of Surgery 32 863-872. (https://doi.org/10.1007/s00268-007-9402-y)

Capdevila J, Iglesias L, Halperin I, Segura A, Martinez-Trufero J, Vaz MA, Corral J, Obiols G, Grande E, Grau JJ, et al. 2012 Sorafenib in metastatic thyroid cancer. Endocrine-Related Cancer 19 209-216. (https://doi.org/10.1530/ERC-11-0351)

Carlomagno F, Vitagliano D, Guida T, Ciardiello F, Tortora G, Vecchio G, Ryan AJ, Fontanini G, Fusco A \& Santoro M 2002 ZD6474, an orally available inhibitor of KDR tyrosine kinase activity, efficiently blocks oncogenic RET kinases. Cancer Research 62 7284-7290.

Carlson KM, Bracamontes J, Jackson CE, Clark R, Lacroix A, Wells SA Jr \& Goodfellow PJ 1994 Parent-of-origin effects in multiple endocrine neoplasia type 2B. American Journal of Human Genetics 55 1076-1082.

Cerutti JM \& Maciel RM 2013 An unusual genotype-phenotype correlation in MEN 2 patients: should screening for RET double germline mutations be performed to avoid misleading diagnosis and treatment? Clinical Endocrinology 79 591-592. (https://doi. org/10.1111/cen.12155)

Cohen EE, Rosen LS, Vokes EE, Kies MS, Forastiere AA, Worden FP, Kane MA, Sherman E, Kim S, Bycott P, et al. 2008 Axitinib is an active treatment for all histologic subtypes of advanced thyroid cancer: results from a phase II study. Journal of Clinical Oncology 26 4708-4713. (https://doi.org/10.1200/JCO.2007.15.9566)

Crockett DK, Piccolo SR, Ridge PG, Margraf RL, Lyon E, Williams MS \& Mitchell JA 2011 Predicting phenotypic severity of uncertain gene variants in the RET proto-oncogene. PLOS ONE 6 e18380. (https://doi.org/10.1371/journal.pone.0018380)

Decker RA \& Peacock ML 1998 Occurrence of MEN 2a in familial Hirschsprung's disease: a new indication for genetic testing of the RET proto-oncogene. Journal of Pediatric Surgery 33 207-214. (https://doi.org/10.1016/S0022-3468(98)90433-X)

Deutschbein T, Matuszczyk A, Moeller LC, Unger N, Yuece A, Lahner H, Mann K \& Petersenn S 2011 Treatment of advanced medullary thyroid carcinoma with a combination of cyclophosphamide, vincristine, and dacarbazine: a single-center experience. Experimental and Clinical Endocrinology and Diabetes 119 540-543. (https://doi. org/10.1055/s-0031-1279704)

Donis-Keller H, Dou S, Chi D, Carlson KM, Toshima K, Lairmore TC, Howe JR, Moley JF, Goodfellow P \& Wells SA Jr 1993 Mutations in the RET proto-oncogene are associated with MEN 2A and FMTC. Human Molecular Genetics 2 851-856. (https://doi.org/10.1093/ $\mathrm{hmg} / 2.7 .851)$

Druker BJ, Talpaz M, Resta DJ, Peng B, Buchdunger E, Ford JM, Lydon NB, Kantarjian H, Capdeville R, Ohno-Jones S, et al. 2001 Efficacy and safety of a specific inhibitor of the BCR-ABL tyrosine kinase in chronic myeloid leukemia. New England Journal of Medicine 344 1031-1037. (https://doi.org/10.1056/NEJM200104053441401)

Elisei R, Cosci B, Romei C, Bottici V, Renzini G, Molinaro E, Agate L, Vivaldi A, Faviana P, Basolo F, et al. 2008 Prognostic significance of somatic RET oncogene mutations in sporadic medullary thyroid cancer: a 10-year follow-up study. Journal of Clinical Endocrinology and Metabolism 93 682-687. (https://doi. org/10.1210/jc.2007-1714)

Elisei R, Schlumberger MJ, Muller SP, Schoffski P, Brose MS, Shah MH, Licitra L, Jarzab B, Medvedev V, Kreissl MC, et al. 2013 Cabozantinib in progressive medullary thyroid cancer. Journal of Clinical Oncology 31 3639-3646. (https://doi.org/10.1200/JCO.2012.48.4659)

Eng C, Smith DP, Mulligan LM, Nagai MA, Healey CS, Ponder MA, Gardner E, Scheumann GF, Jackson CE, Tunnacliffe A, et al. 1994 Point mutation within the tyrosine kinase domain of the RET protooncogene in multiple endocrine neoplasia type $2 \mathrm{~B}$ and related sporadic tumours. Human Molecular Genetics 3 237-241. (https://doi. org $/ 10.1093 / \mathrm{hmg} / 3.2 .237)$

Eng C, Mulligan LM, Smith DP, Healey CS, Frilling A, Raue F, Neumann HP, Ponder MA \& Ponder BA 1995 Low frequency of germline mutations in the RET proto-oncogene in patients with apparently sporadic medullary thyroid carcinoma. Clinical Endocrinology 43 123-127. (https://doi.org/10.1111/j.1365-2265.1995. tb01903.x)

Farndon JR, Leight GS, Dilley WG, Baylin SB, Smallridge RC, Harrison TS \& Wells SA Jr 1986 Familial medullary thyroid carcinoma without associated endocrinopathies: a distinct clinical entity. British Journal of Surgery 73 278-281. (https://doi.org/10.1002/ bjs.1800730411)

Fox E, Widemann BC, Chuk MK, Marcus L, Aikin A, Whitcomb PO, Merino MJ, Lodish M, Dombi E, Steinberg SM, et al. 2013 Vandetanib in children and adolescents with multiple endocrine neoplasia type 2B associated medullary thyroid carcinoma. Clinical Cancer Research 19 4239-4248. (https://doi.org/10.1158/1078-0432. CCR-13-0071)

Franc S, Niccoli-Sire P, Cohen R, Bardet S, Maes B, Murat A, Krivitzky A, Modigliani E \& French Medullary Study G 2001 Complete surgical 
lymph node resection does not prevent authentic recurrences of medullary thyroid carcinoma. Clinical Endocrinology 55 403-409. (https://doi.org/10.1046/j.1365-2265.2001.01339.x)

Frank-Raue K, Fabel M, Delorme S, Haberkorn U \& Raue F 2007 Efficacy of imatinib mesylate in advanced medullary thyroid carcinoma. European Journal of Endocrinology 157 215-220. (https://doi. org/10.1530/EJE-06-0695)

Gagel RF, Levy ML, Donovan DT, Alford BR, Wheeler T \& Tschen JA 1989 Multiple endocrine neoplasia type $2 \mathrm{a}$ associated with cutaneous lichen amyloidosis. Annals of Internal Medicine $\mathbf{1 1 1}$ 802-806. (https://doi.org/10.7326/0003-4819-111-10-802)

Gimm O, Marsh DJ, Andrew SD, Frilling A, Dahia PL, Mulligan LM, Zajac JD, Robinson BG \& Eng C 1997 Germline dinucleotide mutation in codon 883 of the RET proto-oncogene in multiple endocrine neoplasia type $2 \mathrm{~B}$ without codon 918 mutation. Journal of Clinical Endocrinology and Metabolism 82 3902-3904. (https://doi. org/10.1210/jcem.82.11.4508)

Gottlieb JA, Hill CS Jr, Ibanez ML \& Clark RL 1972 Chemotherapy of thyroid cancer. An evaluation of experience with 37 patients. Cancer 30 848-853. (https://doi.org/10.1002/10970142(197209)30:3<848::AID-CNCR2820300336>3.0.CO;2-2)

de Groot JW, Zonnenberg BA, van Ufford-Mannesse PQ, de Vries MM, Links TP, Lips CJ \& Voest EE 2007 A phase II trial of imatinib therapy for metastatic medullary thyroid carcinoma. Journal of Clinical Endocrinology and Metabolism 92 3466-3469. (https://doi. org/10.1210/jc.2007-064)

Hazard JB, Hawk WA \& Crile G Jr 1959 Medullary (solid) carcinoma of the thyroid; a clinicopathologic entity. Journal of Clinical Endocrinology and Metabolism 19 152-161. (https://doi.org/10.1210/ jcem-19-1-152)

Hochhaus A, Larson RA, Guilhot F, Radich JP, Branford S, Hughes TP, Baccarani M, Deininger MW, Cervantes F, Fujihara S, et al. 2017 Long-term outcomes of imatinib treatment for chronic myeloid leukemia. New England Journal of Medicine 376 917-927. (https://doi. org/10.1056/NEJMoa1609324)

Hong DS, Cabanillas ME, Wheler J, Naing A, Tsimberidou AM, Ye L, Busaidy NL, Waguespack SG, Hernandez M, El Naggar AK, et al. 2011 Inhibition of the Ras/Raf/MEK/ERK and RET kinase pathways with the combination of the multikinase inhibitor sorafenib and the farnesyltransferase inhibitor tipifarnib in medullary and differentiated thyroid malignancies. Journal of Clinical Endocrinology and Metabolism 96 997-1005. (https://doi.org/10.1210/jc.2010-1899)

Hughes JMS, John H, Dougald C, MacGillivray, Howard R, Malchoff CD \& Malchoff DM 1996 The Sipple syndrome: from clinical description genetic analysis in the index family. Endocrinologist 6 427-430. (https://doi.org/10.1097/00019616-199611000-00002)

Husain M, Alsever RN, Lock JP, George WF \& Katz FH 1978 Failure of medullary carcinoma of the thyroid to respond to doxorubicin therapy. Hormone Research 9 22-25. (https://doi. org/10.1159/000178893)

Imai T, Uchino S, Okamoto T, Suzuki S, Kosugi S, Kikumori T, Sakurai A \& Japan MENCo 2013 High penetrance of pheochromocytoma in multiple endocrine neoplasia 2 caused by germ line RET codon 634 mutation in Japanese patients. European Journal of Endocrinology 168 683-687. (https://doi.org/10.1530/EJE-12-1106)

Jasim S, Ying AK, Waguespack SG, Rich TA, Grubbs EG, Jimenez C, Hu MI, Cote G \& Habra MA 2011 Multiple endocrine neoplasia type $2 \mathrm{~B}$ with a RET proto-oncogene A883F mutation displays a more indolent form of medullary thyroid carcinoma compared with a RET M918T mutation. Thyroid 21 189-192. (https://doi.org/10.1089/ thy.2010.0328)

Kihara M, Miyauchi A, Yoshioka K, Oda H, Nakayama A, Sasai H, Yabuta T, Masuoka H, Higashiyama T, Fukushima M, et al. 2016 Germline RET mutation carriers in Japanese patients with apparently sporadic medullary thyroid carcinoma: A single institution experience. Auris Nasus Larynx 43 551-555. (https://doi. org/10.1016/j.anl.2015.12.016)

Kurzrock R, Sherman SI, Ball DW, Forastiere AA, Cohen RB, Mehra R, Pfister DG, Cohen EE, Janisch L, Nauling F, et al. 2011 Activity of XL184 (Cabozantinib), an oral tyrosine kinase inhibitor, in patients with medullary thyroid cancer. Journal of Clinical Oncology $\mathbf{2 9}$ 2660-2666. (https://doi.org/10.1200/JCO.2010.32.4145)

Lairmore TC, Ball DW, Baylin SB \& Wells SA Jr 1993 Management of pheochromocytomas in patients with multiple endocrine neoplasia type 2 syndromes. Annals of Surgery 217 595-601. (https://doi. org/10.1097/00000658-199306000-00001)

Lam ET, Ringel MD, Kloos RT, Prior TW, Knopp MV, Liang J, Sammet S, Hall NC, Wakely PE Jr, Vasko VV, et al. 2010 Phase II clinical trial of sorafenib in metastatic medullary thyroid cancer. Journal of Clinical Oncology 28 2323-2330. (https://doi.org/10.1200/JCO.2009.25.0068)

Laure Giraudet A, Al Ghulzan A, Auperin A, Leboulleux S, Chehboun A, Troalen F, Dromain C, Lumbroso J, Baudin E \& Schlumberger M 2008 Progression of medullary thyroid carcinoma: assessment with calcitonin and carcinoembryonic antigen doubling times. European Journal of Endocrinology 158 239-246. (https://doi.org/10.1530/EJE-07-0667)

Lips CJ, Landsvater RM, Hoppener JW, Geerdink RA, Blijham GH, Jansen-Schillhorn van Veen JM, Feldberg MA, van Gils AP, Hoogenboom H, Berends MJ, et al. 1995 From medical history and biochemical tests to presymptomatic treatment in a large MEN $2 \mathrm{~A}$ family. Journal of Internal Medicine 238 347-356. (https://doi. org/10.1111/j.1365-2796.1995.tb01209.x)

Marsh DJ, McDowall D, Hyland VJ, Andrew SD, Schnitzler M, Gaskin EL, Nevell DF, Diamond T, Delbridge L, Clifton-Bligh P, et al. 1996 The identification of false positive responses to the pentagastrin stimulation test in RET mutation negative members of MEN 2A families. Clinical Endocrinology 44 213-220. (https://doi. org/10.1046/j.1365-2265.1996.505292.x)

Modigliani E, Vasen HM, Raue K, Dralle H, Frilling A, Gheri RG, Brandi ML, Limbert E, Niederle B, Forgas L, et al. 1995 Pheochromocytoma in multiple endocrine neoplasia type 2: European study. The Euromen Study Group. Journal of Internal Medicine $\mathbf{2 3 8}$ 363-367. (https://doi.org/10.1111/j.1365-2796.1995.tb01211.x)

Moley JF 2010 Medullary thyroid carcinoma: management of lymph node metastases. Journal of the National Comprehensive Cancer Network 8 549-556. (https://doi.org/10.6004/jnccn.2010.0042)

Moura MM, Cavaco BM, Pinto AE \& Leite V 2011 High prevalence of RAS mutations in RET-negative sporadic medullary thyroid carcinomas. Journal of Clinical Endocrinology and Metabolism 96 E863-E868. (https://doi.org/10.1210/jc.2010-1921)

Moura MM, Cavaco BM \& Leite V 2015 RAS proto-oncogene in medullary thyroid carcinoma. Endocrine-Related Cancer 22 R235-R252. (https://doi.org/10.1530/ERC-15-0070)

Mulligan LM, Kwok JB, Healey CS, Elsdon MJ, Eng C, Gardner E, Love DR, Mole SE, Moore JK, Papi L, et al. 1993 Germ-line mutations of the RET proto-oncogene in multiple endocrine neoplasia type $2 \mathrm{~A}$. Nature 363 458-460. (https://doi.org/10.1038/363458a0)

Mulligan LM, Eng C, Attie T, Lyonnet S, Marsh DJ, Hyland VJ, Robinson BG, Frilling A, Verellen-Dumoulin C, Safar A, et al. 1994 Diverse phenotypes associated with exon 10 mutations of the RET proto-oncogene. Human Molecular Genetics 3 2163-2167. (https://doi. org $/ 10.1093 / \mathrm{hmg} / 3.12 .2163)$

Nakamura T, Ishizaka Y, Nagao M, Hara M \& Ishikawa T 1994 Expression of the ret proto-oncogene product in human normal and neoplastic tissues of neural crest origin. Journal of Pathology $\mathbf{1 7 2}$ 255-260. (https://doi.org/10.1002/path.1711720305)

Neumann HP, Vortmeyer A, Schmidt D, Werner M, Erlic Z, Cascon A, Bausch B, Januszewicz A \& Eng C 2007 Evidence of MEN-2 in the original description of classic pheochromocytoma. New England Journal of Medicine 357 1311-1315. (https://doi.org/10.1056/ NEJMoa071407) 
Nunziata V, Giannattasio R, Di Giovanni G, D'Armiento MR \& Mancini M 1989 Hereditary localized pruritus in affected members of a kindred with multiple endocrine neoplasia type 2A (Sipple's syndrome). Clinical Endocrinology 30 57-63. (https://doi. org/10.1111/j.1365-2265.1989.tb03727.x)

Oliveira MN, Hemerly JP, Bastos AU, Tamanaha R, Latini FR, Camacho CP, Impellizzeri A, Maciel RM \& Cerutti JM 2011 The RET p.G533C mutation confers predisposition to multiple endocrine neoplasia type $2 \mathrm{~A}$ in a Brazilian kindred and is able to induce a malignant phenotype in vitro and in vivo. Thyroid 21 975-985. (https://doi.org/10.1089/thy.2010.0190)

Pelizzo MR, Boschin IM, Bernante P, Toniato A, Piotto A, Pagetta C, Nibale O, Rampin L, Muzzio PC \& Rubello D 2007 Natural history, diagnosis, treatment and outcome of medullary thyroid cancer: 37 years experience on 157 patients. European Journal of Surgical Oncology 33 493-497. (https://doi.org/10.1016/j.ejso.2006.10.021)

Qi XP, Zhao JQ, Chen ZG, Cao JL, Du J, Liu NF, Li F, Sheng M, Fu E, Guo J, et al. 2015 RET mutation p.S891A in a Chinese family with familial medullary thyroid carcinoma and associated cutaneous amyloidosis binding OSMR variant p.G513D. Oncotarget 6 33993-34003. (https://doi.org/10.18632/oncotarget.4992)

Ravaud A, de la Fouchardiere C, Asselineau J, Delord JP, Do Cao C, Niccoli P, Rodien P, Klein M \& Catargi B 2010 Efficacy of sunitinib in advanced medullary thyroid carcinoma: intermediate results of phase II THYSU. Oncologist 15 212-213. (https://doi. org/10.1634/2009-0303)

Robinson BG, Paz-Ares L, Krebs A, Vasselli J \& Haddad R 2010 Vandetanib (100 $\mathrm{mg})$ in patients with locally advanced or metastatic hereditary medullary thyroid cancer. Journal of Clinical Endocrinology and Metabolism 95 2664-2671. (https://doi.org/10.1210/jc.20092461)

Rodriguez JM, Balsalobre M, Ponce JL, Rios A, Torregrosa NM, Tebar J \& Parrilla P 2008 Pheochromocytoma in MEN 2A syndrome. Study of 54 patients. World Journal of Surgery 32 2520-2526. (https://doi. org/10.1007/s00268-008-9734-2)

Romei C, Cosci B, Renzini G, Bottici V, Molinaro E, Agate L, Passannanti P, Viola D, Biagini A, Basolo F, et al. 2011 RET genetic screening of sporadic medullary thyroid cancer (MTC) allows the preclinical diagnosis of unsuspected gene carriers and the identification of a relevant percentage of hidden familial MTC (FMTC). Clinical Endocrinology 74 241-247. (https://doi. org/10.1111/j.1365-2265.2010.03900.x)

Romeo G, Ronchetto P, Luo Y, Barone V, Seri M, Ceccherini I, Pasini B, Bocciardi R, Lerone M, Kaariainen H, et al. 1994 Point mutations affecting the tyrosine kinase domain of the RET proto-oncogene in Hirschsprung's disease. Nature 367 377-378. (https://doi. org/10.1038/367377a0)

Rothberg AE, Raymond VM, Gruber SB \& Sisson J 2009 Familial medullary thyroid carcinoma associated with cutaneous lichen amyloidosis. Thyroid 19 651-655. (https://doi.org/10.1089/ thy.2009.0021)

Scapineli JO, Ceolin L, Punales MK, Dora JM \& Maia AL 2016 MEN 2A-related cutaneous lichen amyloidosis: report of three kindred and systematic literature review of clinical, biochemical and molecular characteristics. Familial Cancer 15 625-633. (https://doi.org/10.1007/ s10689-016-9892-6)

Scherubl H, Raue F \& Ziegler R 1990 Combination chemotherapy of advanced medullary and differentiated thyroid cancer. Phase II study. Journal of Cancer Research and Clinical Oncology 116 21-23. (https://doi.org/10.1007/BF01612635)

Schlumberger MJ, Elisei R, Bastholt L, Wirth LJ, Martins RG, Locati LD, Jarzab B, Pacini F, Daumerie C, Droz JP, et al. 2009 Phase II study of safety and efficacy of motesanib in patients with progressive or symptomatic, advanced or metastatic medullary thyroid cancer. Journal of Clinical Oncology 27 3794-3801. (https://doi.org/10.1200/ JCO.2008.18.7815)
Scholten A, Valk GD, Ulfman D, Borel Rinkes IH \& Vriens MR 2011 Unilateral subtotal adrenalectomy for pheochromocytoma in multiple endocrine neoplasia type 2 patients: a feasible surgical strategy. Annals of Surgery 254 1022-1027. (https://doi.org/10.1097/ SLA.0b013e318237480c)

Scollo C, Baudin E, Travagli JP, Caillou B, Bellon N, Leboulleux S \& Schlumberger M 2003 Rationale for central and bilateral lymph node dissection in sporadic and hereditary medullary thyroid cancer. Journal of Clinical Endocrinology and Metabolism 88 2070-2075. (https://doi.org/10.1210/jc.2002-021713)

Sijmons RH, Hofstra RM, Wijburg FA, Links TP, Zwierstra RP, Vermey A, Aronson DC, Tan-Sindhunata G, Brouwers-Smalbraak GJ, Maas SM, et al. 1998 Oncological implications of RET gene mutations in Hirschsprung's disease. Gut 43 542-547. (https://doi.org/10.1136/ gut.43.4.542)

Sipple J 1961 The association of pheochromocytoma and thyroid cancer. American Journal of Medicine 31 163-166. (https://doi. org/10.1016/0002-9343(61)90234-0)

Sipple JH 1984 Multiple endocrine neoplasia type 2 syndromes: historical perspectives. Henry Ford Hospital Medical Journal 32 219-221.

Skinner MA, Moley JA, Dilley WG, Owzar K, Debenedetti MK \& Wells SA Jr 2005 Prophylactic thyroidectomy in multiple endocrine neoplasia type 2A. New England Journal of Medicine 353 1105-1113. (https://doi.org/10.1056/NEJMoa043999)

Steiner AL, Goodman AD \& Powers SR 1968 Study of a kindred with pheochromocytoma, medullary thyroid carcinoma, hyperparathyroidism and Cushing's disease: multiple endocrine neoplasia, type 2. Medicine 47 371-409. (https://doi. org/10.1097/00005792-196809000-00001)

Telenius-Berg M, Berg B, Hamberger B, Tibblin S, Tisell LE, Ysander L \& Welander G 1984 Impact of screening on prognosis in the multiple endocrine neoplasia type 2 syndromes: natural history and treatment results in 105 patients. Henry Ford Hospital Medical Journal 32 225-231.

Tuttle RM, Haddad RI, Ball DW, Byrd D, Dickson P, Duh QY, Ehya H, Haymart M, Hoh C, Hunt JP, et al. 2014 Thyroid carcinoma, version 2.2014. Journal of the National Comprehensive Cancer Network 12 1671-1680. (https://doi.org/10.6004/jnccn.2014.0169)

Verga U, Fugazzola L, Cambiaghi S, Pritelli C, Alessi E, Cortelazzi D, Gangi E \& Beck-Peccoz P 2003 Frequent association between MEN 2A and cutaneous lichen amyloidosis. Clinical Endocrinology 59 156-161. (https://doi.org/10.1046/j.1365-2265.2003.01782.x)

Weber T, Schilling T, Frank-Raue K, Colombo-Benkmann M, Hinz U, Ziegler R \& Klar E 2001 Impact of modified radical neck dissection on biochemical cure in medullary thyroid carcinomas. Surgery 130 1044-1049. (https://doi.org/10.1067/msy.2001.118380a)

Wells SA Jr, Gosnell JE, Gagel RF, Moley J, Pfister D, Sosa JA, Skinner M, Krebs A, Vasselli J \& Schlumberger M 2010 Vandetanib for the treatment of patients with locally advanced or metastatic hereditary medullary thyroid cancer. Journal of Clinical Oncology 28 767-772. (https://doi.org/10.1200/JCO.2009.23.6604)

Wells SA Jr, Robinson BG, Gagel RF, Dralle H, Fagin JA, Santoro M, Baudin E, Elisei R, Jarzab B, Vasselli JR, et al. 2012 Vandetanib in patients with locally advanced or metastatic medullary thyroid cancer: a randomized, double-blind phase III trial. Journal of Clinical Oncology 30 134-141. (https://doi. org/10.1200/ JCO.2011.35.5040)

Wells SA Jr, Pacini F, Robinson BG \& Santoro M 2013 Multiple endocrine neoplasia type 2 and familial medullary thyroid carcinoma: an update. Journal of Clinical Endocrinology and Metabolism 98 3149-3164. (https://doi.org/10.1210/jc.2013-1204)

Wells SA Jr, Asa SL, Dralle H, Elisei R, Evans DB, Gagel RF, Lee N, Machens A, Moley JF, Pacini F, et al. 2015 Revised American Thyroid Association guidelines for the management of medullary thyroid carcinoma. Thyroid 25 567-610. (https://doi.org/10.1089/ thy.2014.0335) 
Wermer P 1954 Genetic aspects of adenomatosis of endocrine glands. American Journal of Medicine 16 363-371. (https://doi. org/10.1016/0002-9343(54)90353-8)

Williams ED \& Pollock DJ 1966 Multiple mucosal neuromata with endocrine tumours: a syndrome allied to von Recklinghausen's disease. Journal of Pathology and Bacteriology 91 71-80. (https://doi. org/10.1002/path.1700910109)

Wu LT, Averbuch SD, Ball DW, de Bustros A, Baylin SB \& McGuire WP 3rd 1994 Treatment of advanced medullary thyroid carcinoma with a combination of cyclophosphamide, vincristine, and dacarbazine. Cancer 73 432-436. (https://doi.org/10.1002/1097-

0142(19940115)73:2<432::AID-CNCR2820730231>3.0.CO;2-K)
Yakes FM, Chen J, Tan J, Yamaguchi K, Shi Y, Yu P, Qian F, Chu F, Bentzien F, Cancilla B, et al. 2011 Cabozantinib (XL184), a novel MET and VEGFR2 inhibitor, simultaneously suppresses metastasis, angiogenesis, and tumor growth. Molecular Cancer Therapeutics 10 2298-2308. (https://doi.org/10.1158/1535-7163. MCT-11-0264)

Zenaty D, Aigrain Y, Peuchmaur M, Philippe-Chomette P, Baumann C, Cornelis F, Hugot JP, Chevenne D, Barbu V, Guillausseau PJ, et al. 2009 Medullary thyroid carcinoma identified within the first year of life in children with hereditary multiple endocrine neoplasia type $2 \mathrm{~A}$ (codon 634) and 2B. European Journal of Endocrinology 160 807-813. (https://doi.org/10.1530/EJE-08-0854)

Received in final form 7 September 2017

Accepted 6 November 2017

Accepted preprint published online 15 November 2017 